RAÚL EDUARDO

CABRERA-AMADOR

ALICIA MARÍA

VIZCAIINO-TORRES

MANUELLA CANO-BROUTÉ
Universidad Autónoma Metropolitana. CDMX, México raulcamador@gmail.com

alicevt24@gmail.com

manubrute@gmail.com

\title{
Estética y política de la ocupación del espacio público. Una propuesta de análisis
}




\section{AESTHETICS AND POLITICS OF THE OCCUPATION OF PUBLIC} SPACE. AN ANALYSIS PROPOSAL

\section{ABSTRACT}

The present article is a methodological proposal that arises from the question about the relationship between aesthetics and politics. Where aesthetics is related to the public space and to artistic expressions that bring into play modes of political confrontation, rather than to the beauty of things. Throughout the essay, an analysis is proposed in order to explore these expressions. It is not meant to be a rigorous model but should rather work as a series of conceptual and methodological tools to serve the researcher interested in the field of art and politics.

\section{Keywords}

Art, politics, artistic expressions, public space.

\section{RESUMEN}

El presente trabajo es una propuesta metodológica que surge de la pregunta por la relación entre estética y política. En donde la estética se deslinda de su común asociación a lo bello y se piensa más bien en relación al espacio público y a las expresiones artísticas que ponen en juego modos de confrontación política. Se propone un análisis para explorar estas expresiones que no trata de un modelo riguroso, sino de herramientas conceptuales y metodológicas que sirvan para el investigador.

\section{Palabras clave}

Arte, política, expresiones artísticas, espacio público. 
El valor cultural como tal parece hoy inducir a que la obra de arte se mantenga oculta.

Walter Benjamin

...y los colores vivos ásperos ligeros sutiles

luchan se alteran, se exaltan se ensordecen dejan filtrar

una trasparencia inesperada

Bram Van Velde

\section{INTRODUCCIÓN}

Nuestras sociedades parecen estar marcadas por una necesidad, cada vez más presente, de habitar el espacio público a través del arte callejero: la gráfica, el performance, la escultura, el teatro, la música y la danza son algunos ejemplos. Las últimas movilizaciones sociales, en ciudades como Buenos Aires, Santiago de Chile y Ciudad de México así como las acciones de diversos colectivos de jóvenes que se han formado ante un panorama de precariedad laboral y la ausencia de vínculos afectivos, han recurrido a diversas técnicas artísticas para expresar un malestar social que los atraviesa de maneras particulares. Como menciona García Canal “(...) hay una circulación incesante de cuerpos que hacen uso, dejando su huella, de los espacios urbanos y expresan, con humor e ironía, el malestar que los consume" (2006, p.79). Es por ello que, actualmente, la creación artística está cada vez más cerca de la vida diaria y más lejos de las instituciones culturales.

Al intentar acercarnos a diversas expresiones presentes en los muros, en las plazas, en los espacios de transporte público, resaltan imágenes que confrontan al espectador y lo invitan a cambiar su percepción sensorial de la calle. Cotidianamente nos encontramos absorbidos por la presencia del tránsito de personas y de coches, sobre un telón de fondo donde los edificios, los inmuebles que embellecen los barrios residenciales en contraposición a los que existen en los caseríos raídos y desgastados de los suburbios populares, representan el valor primordial. La expresión estética de la plástica, del performance, del arte callejero le devuelve al espacio público una condición que le había sido sustraída al paisaje urbano, cada vez más atiborrado de plazas comerciales y anuncios a gran escala que limitan la mirada sobre la ciudad. El horizonte adquiere un aura distinta cuando se entremezclan objetos y escenarios que reconfiguran el campo de lo visual, expresando una necesidad de apropiarse de estructuras de concreto, que han sido creadas al margen de sus habitantes, despojándolos de su capacidad de participar en la creación de las imágenes que lo conforman.

Ahora bien, muchas de estas expresiones no representan únicamente una necesidad de apropiación del paisaje urbano. Hay en ellas manifestaciones que expresan un rechazo a los modos de distribución y significación de la vida en las ciudades. No es que en sí se lo propongan 
como meta de la obra expuesta en la calle, sino que hacen visible en el acto una historia, un drama, un testimonio de personas que han sido privadas de un lugar y de un derecho como habitantes de la ciudad. La obra artística plasmada en el espacio urbano enuncia, en estos casos, perspectivas del mundo que han quedado marginadas de un contacto y un encuentro con el otro. De esta manera, entran en confrontación con modos dominantes de expresión que le asignan lugares donde esas voces y esas imágenes no son escuchadas o vistas, o bien son denostadas por los medios de comunicación. Es precisamente en este ámbito donde es posible acercarse a una mirada que vincula la estética con la política, es decir, a un sitio donde emerge una zona de indeterminación que abre la existencia de la obra plasmada en el espacio público, a la resignificación de un mundo que ha sido impuesto por los valores del mercado. Pero ¿cómo acceder a un análisis que ponga sobre la mesa el sentido que adquieren estas formas de expresión artística? En este artículo proponemos algunas claves de análisis que no operan como un procedimiento rígido y acabado, sino como herramientas conceptuales y metodológicas con las que el investigador puede dialogar.

\section{Arte y política como campos de concurrencia}

El punto de partida para pensar y llevar a cabo un análisis de estas expresiones, que vinculan al arte con la política y viceversa es, como señala Rancière, que el arte no es político por el tipo de mensaje que transmite sobre el orden del mundo, ni por la forma en que representa las estructuras de la sociedad, los conflictos o las identidades de los grupos sociales. Esto implica que no estamos partiendo del régimen de la representación mimética, en donde hay una intención clara de parte del artista, plasmada en su obra, que llega al receptor casi sin problema (Capasso y Bugone, 2016, p.125). Un ejemplo es el arte militante del que Nelly Richard (citada en Capasso y Bugone, 2016) habla, el cual se popularizó en los años sesenta y consiste en murales que retratan al pueblo y que, de cierta forma, pretendían educar a la sociedad con ideas y valores específicos. Para abordar la relación entre la política y el arte, partimos más bien del régimen estético: "un sensorium específico, es decir, una forma sensible heterogénea que se opone a las de la experiencia ordinaria y, por lo tanto, al orden policial" (Capasso y Bugone, 2016, p.126). Desde esta mirada, el arte no está relacionado con lo bello, sino con aquello que irrumpe en la forma que toma un sistema de relaciones que define lugares y adscripciones sociales, y por tanto se trata de una desconexión, una ruptura respecto de conocimientos técnicos artísticos, fines sociales y formas sensibles de su reproducción. Esta ruptura, que también podemos llamar disenso, es el elemento central de la política y es ahí donde se encuentran el arte y la política. Se trata de un:

\section{entrelazamiento de tres lógicas: la de los espacios estéticos, la del trabajo de la ficción y la de las estrategias metapolíticas. Este entrelazamiento implica también un trenzado singular y contradictorio entre las tres formas de eficacia que he intentado definir: la lógica representativa que quiere producir efectos con las representaciones, la lógica estética que produce efectos por la suspensión de los fines representativos y la lógica ética que quiere que las formas del arte y las formas de la política se identifiquen directamente las unas con las otras. (Rancière, 2008, s/p)}

El arte es político por la manera en que hace suyas las coordenadas propias del tiempo y del espacio, separándose de un régimen que delimita y define las formas de ser, de hacer y de decir que le corresponden, bajo una nomenclatura heterónoma a cada sujeto o grupo social. Es político porque pone en práctica una nueva distribución del espacio material y simbólico 
presente en el paisaje urbano y redefine temporalidades acordes a esta distribución. En palabras de Rancière,

replantea el mundo de la experiencia común como el mundo de una experiencia impersonal compartida. De esta forma, ayuda a crear el tejido de una experiencia común en la que se pueden desarrollar nuevas formas de construir objetos comunes y nuevas posibilidades de enunciación subjetiva. (2019, p.183)

Esta experiencia común está repleta de voces que se enuncian desde lugares determinados, de cuerpos que cumplen diferentes funciones y de objetos perfectamente distribuidos dentro de los espacios que transitamos: un modo de ser de lo social que nos antecede y que difícilmente podríamos pensar de otra manera. En ese sentido, una obra de arte tendría que posibilitar una "ruptura entre sentido y sentido", tener un efecto de desfamiliarización de un mundo dado y propiciar la aparición de nuevos mundos posibles. Para ello, Rancière plantea que deben evitarse los mensajes éticos o pedagógicos que tengan como único fin educar a las masas o transmitir una imagen clara del mundo. Citado en Bishop (2016), el autor afirma que "un arte político apropiado aseguraría, de una vez y por todas, la producción de un efecto doble: la legibilidad de una significación política y un choque sensible o perceptivo causado, por el contrario, por lo extraño e inesperado, por aquello que se resiste a la significación" (2004, p.63). Chantal Mouffe sostiene que el objetivo de las prácticas artísticas debería ser "la producción de nuevas subjetividades y la elaboración de nuevos mundos" (2014, p.95); las piensa como prácticas contrahegemónicas capaces de agitar las formas de identificación al trabajar con los afectos. El supuesto de que estas prácticas "buscan desafiar el consenso existente", nos recuerda el planteamiento de Rancière sobre el régimen estético del arte o la estética de la política. En este sentido, nos interesa mostrar a través de un modo particular de análisis social la manera en que la visibilidad del arte en el espacio público interfiere en la división de lo sensible y en los modos de organización ligados a estos comportamientos. Es decir, la manera en que estas prácticas estéticas alteran el orden consensual y por tanto son, a su vez, prácticas políticas.

Entendemos entonces como experiencia estética en el mundo del arte callejero, la irrupción en el espacio público de intervenciones particulares, que de algún modo, alteran el universo organizado de lo sensible, es decir, que son capaces de producir desplazamientos de las personas y de los colectivos hacia posiciones que no eran habituales en su vida cotidiana. Estos desplazamientos muestran otras alternativas y posibilidades de ordenamiento de la vida social y permiten el reconocimiento de otras potencialidades de los individuos y de nuevas formas de comprensión de lo común a partir de un quiebre en las prácticas acostumbradas.

Partimos entonces del supuesto de que el arte, reconocido como tal, ha sido reservado a los espacios privados para su difusión: museos, galerías, auditorios, teatros etc. Con ello ha establecido una relación de distancia entre el espectador y el autor, otorgándole al primero un lugar centrado en la pasividad contemplativa y al segundo la capacidad y expresión creativa. Nos interesa abordar otra perspectiva de análisis de la creación artística partiendo de la relación entre el arte y la política, pensando que su intersección se produce donde el arte interviene en la constitución de las formas de vida colectiva y apunta a su reconfiguración tal y como lo hemos señalado. El arte es, entonces, una crítica en acto de las formas de organización y de producción de sentido dentro de la sociedad, crítica que se hace visible a través de una experiencia que pone en entredicho las relaciones cotidianas no solamente entre las personas, o entre éstas y las instituciones que las regulan, sino también entre las personas y los objetos materiales 
e inmateriales que están dotados de un valor social. Dicha crítica no tiene necesariamente la finalidad de mostrar la fragilidad argumental en las que se sostienen estas formas de organización y producciones de sentido en la sociedad. Se trata más bien de la fabricación de escenarios que en los hechos experimentan otras maneras de ser y de actuar en el mundo. En ese sentido, la crítica no pretende obtener un poder, un beneficio económico o un estatus para determinadas personas o grupos sociales, remplazando las formas existentes. Más bien suspende la nomenclatura que le otorga valor económico o de prestigio al arte, creando nuevas combinatorias que organizan las formas de vida en común, pero sobre todo, propiciando la aparición de nuevas relaciones entre las personas y los objetos al margen de su valor por la inclusión de estos en el mercado y por tanto, creando nuevos objetos de deseo.

Para pensar en la noción de objetos de deseo y su relación con las nuevas prácticas estético políticas, retomamos dos acercamientos, el primero es en relación a la búsqueda de la completud en la raíz platoniana y el segundo a la condición estructural de la falta como origen del deseo en Freud y Lacan. Siguiendo a estos autores, entendemos la noción de objetos de deseo como aquellos lugares en los que depositamos nuestras carencias y necesidades. Para Freud, el deseo es una noción psíquica que busca producir la satisfacción primera, con ello se refiere a "la aparición de una cierta percepción (...) cuya imagen mnémica queda, de ahí en adelante, asociada a la huella que dejó en la memoria la excitación producida por la necesidad" (19001901, p.557-558). Esta imagen es la que hará que el sujeto persiga esta percepción ya vivida a lo largo de toda su vida, construyendo objetos que lo transporten a ella. Para Platón, el deseo no se vincula únicamente con la necesidad, sino con una búsqueda incesante que los seres hacen de su propio complemento al haber sido escindidos por la divinidad (García, 2013, p.162). Los objetos que creamos, además de suplir una necesidad técnica o estética, nos producen un sentimiento de completud, que en Lacan, para quien el deseo no va encaminado a una satisfacción originaria como piensa Freud, refiere a la falta del "objeto real". Entonces, "el deseo tiene su origen en el otro" (2013, p.320), puesto que no se vive a nivel consciente ni individual, sino que proviene de una estructura lingüística compartida. En ese sentido, algunas esferas sociales como el mercado, los medios de comunicación y, en este caso, el arte institucional que está estrechamente ligado a estos dos primeros, fungen como gestores de deseo, pues “(...) han articulado un efectivo discurso basado en la falta, el cual le ayuda a controlar de modo más depurado el goce ligado al deseo con base en el producto fetiche diluyendo la libido pulsional en objetos que albergan promesas de reconocimiento social" (García, 2013, p.373). La lógica de los recintos museo-galería es, al igual que la lógica mercantil, individualista y narcisista, ya que construye objetos de deseo anclados a un discurso en donde el ser se constituye sólo a través del tener (García, 2013, p.376). Para elucidar esta idea, pensemos en Le Déjeuner sur l'Herbe de Édouard Manet, pintura que forma parte de una de las colecciones más prestigiadas del mundo. En ella vemos una obra única, inigualable en estilo; sin embargo, estas cualidades son producto de un modo de ser del arte que ofrece una ilusión de exclusividad en la que, quien pueda acceder a ella desde su lugar de espectador pasivo, obtendrá cierto reconocimiento social. Para construir nuevos objetos de deseo que ayuden a replantear el mundo de la experiencia común, tendríamos que desplazar el deseo hacia objetos que estén más cerca de la vida diaria y más lejos de los recintos que presentan objetos únicos y exóticos a los que sólo unos pocos tienen acceso.

Si pensamos en "Un violador en tu camino", performance que nació en Chile para darle la vuelta al mundo, inmediatamente recordamos sus estrofas más famosas: "Y la culpa no era mía, ni dónde estaba ni cómo vestía", "el violador eres tú" . Este performance, además de representar 
un modo de ser de lo social en que mujeres de todo el mundo sufren diferentes tipos de violencia machista, física y simbólica, funge como un espacio de enunciación colectiva para aquellas que no tenían voz dentro del orden social. La política, al romper con el orden policial y reconfigurar las formas de distribución de lo sensible, según la expresión de Rancière, da lugar a un proceso de subjetivación, pues quienes no disponían de un lugar en el orden policial o más bien, cuyo lugar era el no lugar, aparecen como sujetos. De esta forma, la subjetivación se entiende como una des-identificación de quienes se mueven de un lugar asignado en el orden policial y en la partición de lo sensible. En el caso de Paste Up Morras, colectiva feminista que trabaja con la técnica del Paste Up en la Ciudad de México y sus alrededores (Cabrera, Cano, Roa y Vizcaíno, 2020), la relación arte-política se hace visible no sólo en las imágenes que estas mujeres pegan en el espacio público y que, muchas veces, contienen mensajes que expresan una perspectiva del mundo, sino en todo el proceso creativo que contempla organizarse, reunirse, y salir a las calles a pegar. Son mujeres que se sublevan contra un orden que las quiere bonitas y recatadas, para mostrarse rebeldes y decididas, y escapar del lugar que se les ha asignado en el orden consensual. Estos ejemplos muestran que la creación artística representa un lugar de enunciación para aquellos a quienes se les fue negada la libertad de expresarse libremente, un lugar de confrontación de los sentidos que compartimos socialmente y que, a su vez, crea nuevas significaciones.

3 El arte callejero. Una mirada analítica

A partir de esta postura en torno a la relación entre el arte y la política, identificamos dos aspectos que resultan relevantes para el análisis de expresiones artísticas: el primero es el uso que se hace del espacio público y el segundo el tipo de relaciones que se gestan con la comunidad. En el primer caso, concebimos el espacio público -siguiendo a Hannah Arendt (2005)- como un modo de aparición de los sujetos en la vida colectiva que transforma los eventos propios de la esfera privada de las personas. Esto ocurre en la medida en que su exposición a los otros, sea a través del diálogo o de la acción, configura un espacio que es común a todos, un espacio de dominio público. Por tanto, se trata de una esfera de la vida donde se organizan y gestionan los intereses comunes y se establecen límites a los intereses privados y particulares que sin embargo, el modelo neoliberal ha tendido a privilegiar. Ahora bien, al hablar del uso del espacio público nos referimos a los modos a través de los cuales cualquiera puede intervenir y hacer visible, publicitar algo que busca comunicar a otros. De las formas posibles de intervención nos interesan aquellas que establecen un modo de relación particular con el paisaje urbano alterando los significados otorgados, sea por las instituciones del Estado o por las empresas del mercado. Ya en un artículo anterior hemos señalado que

La expresión gráfica y su contenido hacen del espacio público no sólo un referente físico (la calle), a través del cual se difunden estas formas de manifestación artística. Representa también un espacio simbólico donde encontramos justamente un modo de confrontación como disputa en torno a los sentidos y significaciones socialmente prevalecientes. (Cabrera, Cano, Roa y Vizcaíno, 2020, p.286)

En el segundo caso, cuando nos referimos al tipo de relaciones que se gestan con la comunidad entendemos que una acción, en este caso artística, que es capaz de producir nuevas maneras de concebir el paisaje urbano y la vida social, no tiene efecto alguno si no es produciendo un encuentro con el otro a través de representaciones que modifican la relación entre lo visible y lo invisible. No se trata de incluir necesariamente al otro en la acción artística, pero tampoco de 
arrojarlo a un mero estatus de espectador. Entendemos el ámbito de relación con la comunidad como la capacidad de expresión pública a través de la gráfica, el performance u otro tipo de expresión artística, para convocar a la opinión del otro, para desestabilizar las figuras y modos de comprensión social acerca de objetos, de relaciones o de formas de ejercicio de la autoridad o del poder. Esta convocatoria y la respuesta en términos de la opinión pública definen una relación entre el acto de producción estética y la comunidad a la cual nos referimos. Si regresamos al ejemplo del performance "Un violador en tu camino", escenificado en múltiples ciudades del mundo, encontramos que ese ámbito de relación entre el acto de escenificación pública y la comunidad trascendió las fronteras locales y regionales convocando a cientos de miles de mujeres en todo el mundo, adquiriendo una dimensión internacional de fuerte impacto. Pero nos preguntamos qué es lo que convoca, por qué un performance como este trasciende la esfera de quienes presenciaron tal evento e hicieron posible su propagación. A reserva de profundizar en diversos aspectos -como el papel que jugaron las redes sociales- encontramos una posible respuesta en la reflexión que hace Foucault (2003) leyendo a Kant sobre un tema tan difícil de asir como es el de la actualidad. Foucault señala al respecto que lo que acontece en la conciencia de aquellos que no son protagonistas o actores del evento, (en el caso que nos ocupa de la expresión artística como modo de confrontación con un orden consensual) toma forma en el entusiasmo por la revolución. Hace sin embargo la aclaración de que no se trata de la revolución como sacudida, sino más bien como espectáculo para quienes lo presencian y no participan en él. Lo importante no está en la revolución en sí misma, sino en el exceso que ésta produce en la mirada del espectador. Hay algo entonces en el ámbito de la representación que el evento artístico confronta en la conciencia de los espectadores produciendo una simpatía, una disposición que se manifiesta por el entusiasmo que despierta.

Por otro lado, Chantal Mouffe plantea que el sistema capitalista moviliza constantemente los deseos de la gente moldeando sus identidades con tal de mantener la hegemonía; entonces, una práctica contrahegemónica debe involucrarse en el mismo terreno al producir o fomentar "otras formas de identificación" (2014, p.97). Un Violador En Tu Camino logró darle la vuelta al mundo probablemente porque además de nombrar y narrar una problemática sumamente grave, sus características como el ritmo, las rimas, su melodía, la coreografía e incluso el vestuario en conjunto logran crear una experiencia estética y trabajar con los afectos. Pues "si las prácticas artísticas pueden desempeñar un papel decisivo en la construcción de nuevas formas de subjetividad, se debe a que, con la utilización de recursos que inducen respuestas emocionales, logran llegar a los seres humanos en el nivel afectivo" (Mouffe, 2014, p.103). Al trabajar con el nivel afectivo puede darse una forma de agitación de las formas de identificación dominantes dando pauta a una reorganización de la comunidad consensual. Así, lo que Mouffe llama afecto, retomando a Spinoza, también puede pensarse en términos de lo que Deleuze y Guattari (1997) llamaron desterritorialización. Es decir, un conjunto de líneas de fuga, de discontinuidades que dejan de pulsar en las direcciones acostumbradas y capturadas en las imágenes convencionales. Con ello, la experiencia estética que trasmite la obra pública detona otro tipo de acercamientos a los modos de comprensión de la escena cultural.

\section{Estrategias metodológicas}

Con estas claves de lectura acerca de la relación entre el arte y la política, es decir, el uso del espacio público y la relación que se gesta con la comunidad podemos llevar a cabo una tarea de investigación y análisis de diversas expresiones urbanas que supone la construcción de al menos tres estrategias metodológicas fundamentales. 
La primera estrategia consiste en el empleo del trabajo etnográfico que permita dar cuenta de los procesos a través de los cuales se produce una alteración del paisaje en el espacio público como producto de la intervención de las y los artistas. Este tipo de trabajo en la investigación se traduce en la elaboración de un relato etnográfico concebido como una descripción que da cuenta de la experiencia vivida por los actores considerando dos aspectos fundamentales: el sentido que toma para ellos esta experiencia y el contexto en el cual la intervención se lleva a cabo. En el primer caso, el investigador debe adentrarse a un campo simbólico que dé cuenta, no de la acción misma de irrumpir el espacio público a través de prácticas artísticas, sino de lo que estas acciones representan para los artistas. En Reflexiones sobre un trabajo de campo en Marruecos, Paul Rabinow (1992) narra su experiencia etnográfica en tierras marroquíes, la cual estuvo fuertemente marcada por una serie de encuentros y desencuentros con los habitantes de este país y, principalmente, con sus informantes. Después de varios meses, Rabinow notó que el trabajo antropológico no tenía que ver con una observación pasiva hacia un otro que, como ingenuamente se creía, ocupa un lugar epistemológico inferior a él, sino que en realidad, se trataba de "(...) un proceso de construcción intersubjetiva de formas liminales de comunicación" (1992, p.144), en donde, tanto el investigador como los actores, crean símbolos que comparten y con los cuales construyen el trabajo de campo en conjunto. Las charlas informales, las entrevistas y las experiencias vividas, son vías para acceder a este campo simbólico. Además, deben considerarse tres niveles de información: lo que las personas hacen, lo que las personas dicen que hacen y el deber hacer. Esto, no para enjuiciar las prácticas de los actores sobre el discurso que sostienen, sino para dar cuenta del sentido que tienen estas experiencias para ellos (Restrepo, 2016, p.29).

En el segundo caso, el contexto en el cual se inscribe la intervención en el espacio público, hace referencia a un modo histórico particular a través del cual se expresa una narrativa consensual que delimita las posibilidades de la experiencia artística en el espacio público. Los últimos periodos de gobierno en México, particularmente el encabezado por Peña Nieto, recurrieron a la criminalización de los jóvenes como respuesta del Estado ante las manifestaciones crecientes de descontento. Algunas de estas manifestaciones están relacionadas con el uso público de los medios de comunicación y la invisibilidad de los jóvenes, la inexistencia de políticas públicas orientadas a la juventud y la violencia de que son objeto por autoridades de los cuerpos policiacos violando derechos humanos fundamentales. Esta condición no puede estar exenta de las expresiones a las que acuden los colectivos de artistas callejeros. Es frente a estas condiciones sociohistóricas que con la intervención artística se abre un modo de disposición de objetos, de imágenes que reconfiguran esas posibilidades presentes en ese contexto particular, dando cabida a reconsiderar sus límites. El artista, en este sentido, encuentra en la experiencia de la calle, un espacio que escapa temporalmente a la normalización del mundo impuesta por ese contexto heterónomo. Es en este espacio de libertad, en el sentido de un ejercicio de desidentificación respecto de lugares y referentes conocidos y asumidos como parte de su experiencia, que se revela la existencia del contexto adverso en el que se inscribe su intervención. Lo que el artista abre según Rancière es "un tejido de inscripciones sensibles totalmente alejadas del mundo de la equivalencia mercantil de los productos" (2005, p.12). El arte urbano en un sentido estricto es insurrección en la medida en que crea modos de apreciación del mundo que entran en tensión con aquellos que conforman un contexto determinado y que son asumidos y normalizados públicamente. 
El relato etnográfico da cuenta, entonces, por una parte, del sentido que la experiencia de intervención artística toma para sus creadores a través de una narrativa que expone el proceso de intervención desde sus momentos de preparación, de acción directa en la calle, hasta el reconocimiento del tipo de interlocución a que da lugar en una comunidad determinada. Por otra parte, busca elaborar descripciones que pretenden vislumbrar algunos elementos propios de ese contexto, que determina en cada momento histórico, la aparición de expresiones estéticas concebidas como bien lo señaló Foucault como una rasgadura de la historia (Allouch, 2015, p.63).

Un ejemplo de ello, es la serie de intervenciones que realizamos con Paste Up Morras como parte de un proyecto de investigación, reuniéndonos con ellas y acompañándolas a pegar sus obras en las calles de la Ciudad de México. Durante este proceso, notamos que, si bien, su trabajo se sitúa y habla de un contexto particular, su que-hacer político no está únicamente en las obras que producen, sino en el proceso de tejer redes entre mujeres y salir a pegar, sin antes buscar un spot adecuado, cuidándose entre ellas de la policía y haciéndose "pie de ladrón ${ }^{20}$ para alcanzar lugares más altos. El siguiente párrafo es un fragmento del relato etnográfico llevado a cabo en el marco del proyecto de investigación mencionado:

\begin{abstract}
Al interior de la calle Regina del centro de la ciudad, se encuentra un callejón cuyas paredes están cubiertas de grafiti. Ahí pegamos nuestras ilustraciones, ayudamos a otras chicas a pegar las suyas y nos cuidamos de los policías. Posteriormente, fuimos a otro espacio solitario que se encuentra a unas cuantas cuadras. Algunas cuidaban un extremo de la calle mientras otras pegaban. En eso Alicia vio un señor que pensó era paramédico, pero resultó ser policía. “iiiR!!!”, gritamos nerviosas, y las que estaban pegando entendieron que era una señal de alerta. Algunas huían lenta y sutilmente y otras se dirigían hacia Brensue, la artista que se esforzaba por terminar de pegar su dibujo a pesar de que el policía se dirigía hacia ella. (Cabrera, Cano, Roa y Vizcaíno, 2020, p.267)
\end{abstract}

4.2 La descripción de las imágenes

La segunda estrategia consiste en la elaboración de una descripción detallada de las imágenes que están presentes en el empleo de la plástica o del performance que se escenifica en el espacio público. Esta descripción debe contemplar detalles aparentemente nimios o poco relevantes de las obras hechas públicas, similar a la descripción que hace José Saramago (1991) del grabado La Crucifixión de Durero al inicio de su obra El Evangelio según Jesucristo. Al encontrarnos ante un panorama transdiciplinario que recurre a una narrativa propia de las ciencias sociales y a expresiones artísticas cuyo carácter reclama otro tipo de sensibilidad, resulta relevante hacer referencia a herramientas que vinculan la observación, la descripción y el análisis de una realidad determinada con una estética de las imágenes como ocurre con la antropología visual. Para ello, partimos del planteamiento de Esteban Krotz (1994), quien considera a la antropología como:

Alteridad, pues, "capta" el fenómeno de lo humano de un modo especial. Nacida del contacto cultural y permanentemente referida a él y remitiendo a él, constituye una aproximación completamente diferente de todos los demás intentos de captar y de comprender el fenómeno humano. Es la categoría central de una pregunta antropológica específica. (p.9) 
Desde esta reflexión, la antropología visual puede pensarse como la alteridad a partir de una imagen; el interés, la curiosidad, asombro o extrañamiento que provoca (Zirión, 2015, p.49). A pesar de que esta disciplina también incluye al cine, en este trabajo hacemos referencia específicamente a la fotografía o al uso de las imágenes estáticas. Francis Galton y Gustave Le Bon consideraban que la fotografía podía servir como herramienta para retratar al no europeo, lo cual implicaba una objetivación de ese otro, cuestión que cambió con las miradas de antropólogos como Margaret Mead, Claude Lévy-Strauss, Franz Boas, Bronislaw Malinowski y John Collier (Balbuena, 2015, p.5). No obstante el intento de Mead por alejarse de la objetividad, en su trabajo de campo en Bali, hacía uso de lo visual -fotografías o filmes- como recurso para acercarse a la objetividad y conseguir eliminar lo subjetivo (Jacknis, 1988, p.172), y en Visual Anthropology in a discipline of words (1975) parece recurrir a lo audiovisual con tal de tener más objetividad y poder documentar las distintas culturas; lo cual continuaba con la objetivación del otro además de ser una forma de colonización que, a pesar de estar presente en la antropología desde su origen, es reforzada por la fotografía y el video.

Para fines de este artículo no pretendemos hacer uso de la fotografía como un recurso para mostrar una tesis como Mead y Bateson lo hicieron con los balineses. Recurrimos a la imagen más bien como punto de partida para la construcción de un análisis de la plástica urbana, pues consideramos que, como menciona Antonio Zirión, en lugar de concebir a la antropología visual como una técnica de registro, se trata de una manera distinta de entender y hacer antropología (2015, p.22): "la imagen no es únicamente un instrumento para la documentación etnográfica, sino un auténtico vehículo de conocimiento; representa una forma distinta de observar, de abordar y analizar la cultura y la sociedad" (Zirión, 2015, p.48). Es así que partiendo de la imagen de un gráfico o de una expresión performativa, proponemos un ejercicio de observación detallada (incluso de lo que pareciera irrelevante) a fin de producir una descripción que recoja las pinceladas aparentemente insignificantes y dé lugar, junto con el relato etnográfico, a la producción de un material para llevar a cabo un análisis de la obra plástica en el espacio público. A continuación presentamos dos ejemplos del tipo de descripción de la que hablamos.

Una reinterpretación de La Virgen de Guadalupe es el objeto de esta imagen. Con colores llamativos y fosforescentes como el amarillo, rosa y negro se despliega en una de las paredes del centro de la Ciudad de México. Esta virgen, con expresión de suplicio, tiene el rostro de una calavera representando la muerte. En México, la virgen juega un papel significativo para la sociedad, muchos la identifican como un sello de la mexicanidad puesto que representa una madre protectora. En el centro de la imagen, donde yace el vestido de la virgen, vemos la frase "ya no estoy yo aquí que soy tu madre soy una más de las nueve mujeres que asesinan en México todos los días". Este texto hace referencia a los feminicidios; pensamos que la virgen está muerta, la mató la sociedad machista mexicana y, al estar muerta, no hay quién haga la función de protección. Podemos observar que justo arriba del texto hay un corazón que se asemeja al sagrado corazón de Jesús, pero éste está roto. La artista, entonces, hace una resignificación del símbolo católico que adoran los mexicanos para transmitir un mensaje político. 


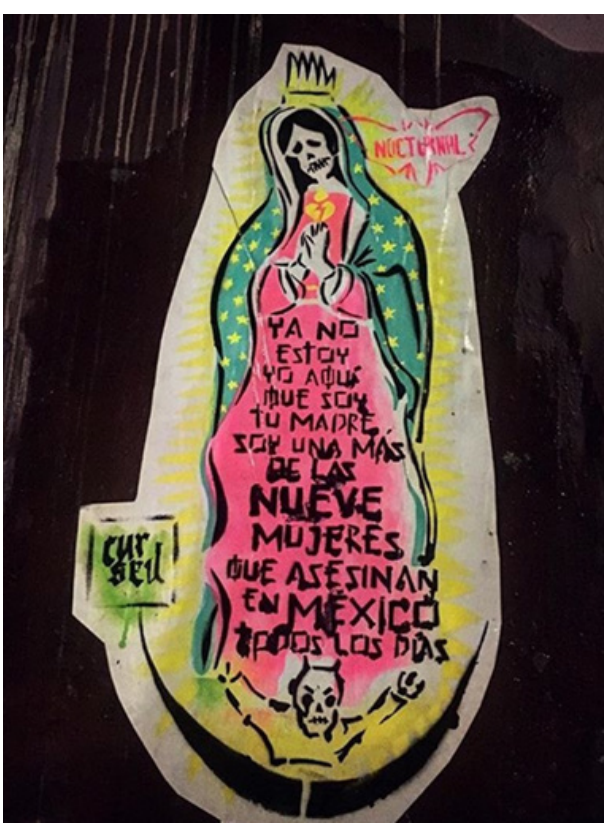

Figura 1. Foto extraída del Instagram de @un_ cursed, obra de Cursed. ${ }^{3}$

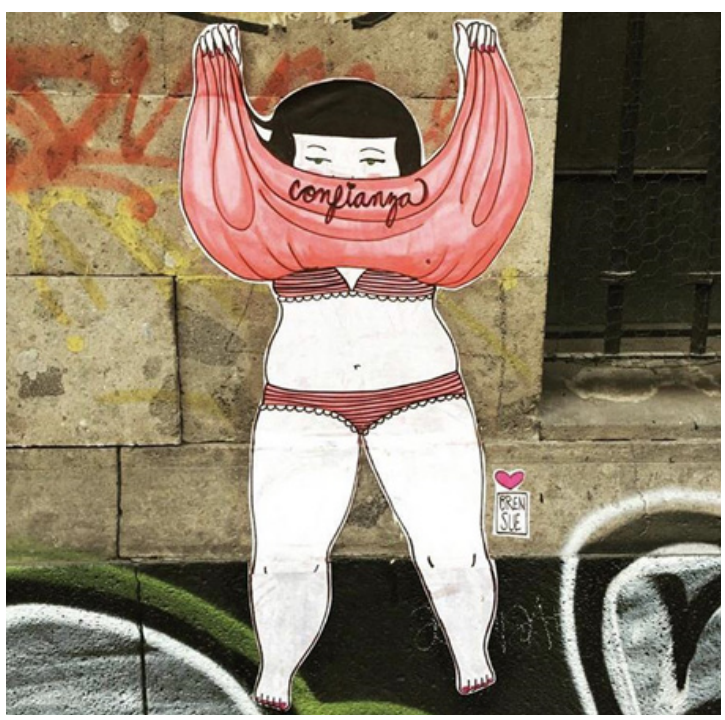

Figura 2. Foto extraída del Instagram de @Brensue, obra de Brensue. $^{4}$

"Lupita", nombre que la autora da a su personaje, se levanta su vestido rosado y muestra su cuerpo con ropa interior. Su panza curvada y piernas anchas nos hacen pensar que la autora tiene un discurso de aceptación del cuerpo femenino dejando a un lado los estereotipos del mismo: esbelto, piernas gruesas, cintura pequeña. Lupita, sin embargo, no deja de ser "femenina"; tiene las uñas pintadas de rosa, ropa interior "coqueta" y un vestido rosa. La frase "confianza" escrita debajo de su rostro, da cuenta de un intento por resignificar el cuerpo femenino, por impulsar la aceptación del mismo y a la vez por la deconstrucción de los estereotipos interiorizados que hacen sentir a las mujeres inseguras por no tener el cuerpo "deseado". La artista muestra el cuerpo femenino como es, sin ser un objeto sexualizado. A un lado de la pierna izquierda se encuentra la firma de la artista.

En ambos casos, la descripción de la imagen recoge elementos visibles que están presentes en la obra, pero también recurre a una interpretación que proyecta de algún modo el tipo de alteraciones, de torsiones al decir de Laura Quintana (2020) que, desde la lectura del investigador o investigadora pueden ser otorgadas a la exposición pública de acuerdo a un conjunto de referentes culturales.

Ahora bien, según la autora María Fernanda Troya, retomando a Poole (2005), en un segundo momento [de la antropología visual], el archivo empieza a llamar la atención de los investigadores, no solamente como lugar en el que las imágenes han sido conservadas, sino que puede ser analizado en sí mismo como una tecnología visual, lo que permite adelantar el análisis sobre la 'raza', por ejemplo, desde la búsqueda de 'significados' y contenidos al interior de las imágenes. (p.23)

Sin embargo, al asumir que hay "significados y contenidos" al interior de la imagen estaríamos 
suponiendo que la imagen existe por sí misma y nos estaríamos olvidando de la mirada. Por otro lado John Collier y Malcom Collier sostienen que la cámara funciona como un objeto para recolectar data, patrones y relaciones (1986, p.17), y la fotografía etnográfica como un instrumento para adquirir una observación más holística cuyos elementos serán leídos exactamente igual por cualquiera. Esta visión anula cualquier posibilidad de interpretación y es importante resaltar que el valor antropológico no reside en la imagen per se, "sino en la mirada, tanto de quien la produce como de quienes la reciben, y en la interpretación que de ella se haga" (Zirión, 2015, p.50) tal y como lo hemos señalado. Aunque haya una cámara de por medio, la mirada siempre va a estar presente, además de que obviamente importa qué es lo que se fotografía, quién ve la foto y cómo la ve. La mirada implica entonces un tránsito entre el objeto que es mirado y el sujeto que de alguna manera escudriña la imagen que tiene frente a sí a través del ojo, expresando con ello el encuentro de su propia subjetividad con la materialidad del objeto estético. Lapoujade (2001) señala que la mirada "Es una vía para salir al mundo o para regresar a sí mismo, es un espejo móvil en que se refleja el otro, lo visto, la alteridad; pero también lo uno, lo vivido, la mismidad" (p.12). Entonces en ese encuentro entre la mirada y el objeto estético se esconde el encuentro entre quien mira el escenario y la manifestación artística urbana presente en él, y por otra parte la mirada del artistita, estableciendo un modo de comunicación que transita al margen de la uniformidad de los símbolos urbanos. La mirada de la gráfica, del performance, del graffiti, representa en este sentido un encuentro, un modo de transmisión que vincula al creador con el espectador en un acto que revela en sí mismo su propia insubordinación.

\subsection{El ensamblaje y el análisis del trabajo etnográfico y la descripción de las imágenes}

La tercera estrategia consiste en el ensamblaje y análisis de las dos estrategias anteriores cuyo soporte es la manera en que este tipo de intervenciones en el espacio público alteran las significaciones socialmente producidas como formas dominantes de concepción del mundo. Para este análisis, que consiste en la relación entre estética y política, recurrimos a tales categorías desde Rancière y Mouffe: disociación, disenso, comunidad consensual, consenso y hegemonía. Consideramos que un análisis social que opera con el empleo de estas nociones es posible y hace referencia a lo que Quintana (2020), siguiendo a Rancière, denomina metodología cartográfica, es decir, modos de intervención en escenarios públicos que operan en universos que organizan lo que al autor denomina división de lo sensible.

Se trata de hacer evidente tanto las características propias de esas formas dominantes de concebir el ser, el hacer y el decir de los sujetos de acuerdo a una estructura social cuyo soporte es la desigualdad, como la producción de nuevas significaciones que resignifican el espacio y el tiempo vividos en común. Tomemos como ejemplo la intervención en el Ángel de la Independencia el 16 de agosto de 2019: un monumento histórico que se encuentra en la zona céntrica de la Ciudad de México y que representa cierta distribución de lo sensible que consiste en una lectura oficial de la historia moderna del país. Se tapizó con dibujos, gráficos y frases de colores brillantes que describían la situación de violencia hacia las mujeres en México. Si "el consenso significa el acuerdo entre sentido y sentido, es decir, entre un modo de presentación sensible y un régimen de interpretación de sus datos" (Rancière, 2010, p.69), esta intervención da pauta a una confrontación de sentidos: la exposición de un México feminicida frente a un nacionalismo machista. Se rompe la relación entre la materialidad del monumento y lo que representa simbólicamente, dando lugar a una agitación de las formas de hacer, ser 
y decir: "algunos dicen, le restan belleza, presencia y simbolismo y que lastiman la identidad cultural nacional" (García, 2019, s/p). Si consideramos que el nacionalismo mexicano está relacionado con una cultura de machismo, el hecho de exponer frases como "la patria mata", "estado opresor", "se va a caer", "policía violador", "asesinos", "México feminicida" sobre un monumento que representa una memoria histórica, da lugar -además de una agitación en el orden consensual- a una subjetivación política de aquellas cuyo lugar era el no lugar, en la medida en que el ejercicio de la violencia de género a la que son sometidas, no es reconocida como un factor determinante de su condición de vida. Otro ejemplo es la intervención del artista polaco Krysztof Wodizcko en el 2001 en Tijuana: los rostros de seis mujeres se proyectaron sobre la fachada de un centro cultural mientras narraban sus experiencias de violencia. Similar a la intervención del Ángel de la Independencia, sobre un símbolo arquitectónico que representa una carga de significaciones sociales, se dispone otro sentido contradictorio al del espacio urbano o monumento, dando lugar a una disputa por las significaciones sociales. Es la ruptura de los referentes de sentido que le permiten a estas imágenes ser parte de un sentido común de lo que es la ciudad. La proyección rompe esa armonía urbana y deja ver otro sentido.

En estas intervenciones artísticas en los espacios públicos, "lo que opera son disociaciones: la ruptura de una relación entre el sentido y el sentido, entre un mundo visible, un modo de afección, un régimen de interpretación y un espacio de posibilidades; es la ruptura de las referencias sensibles que permitían estar en el propio lugar en un orden de las cosas" (Rancière, 2010, p.69). En esta disociación se presenta un disenso respecto a modos de organización del sentido en el espacio público y por lo tanto, un carácter estético y político al mismo tiempo. De esta manera, siguiendo la noción de "sentido común" de Gramsci que retoma Mouffe la cual consiste en la construcción de formas de subjetividad y concepciones particulares del mundo- las prácticas culturales y artísticas son un factor importante para la reproducción o desarticulación del orden hegemónico: "Si es el resultado de una articulación discursiva, el sentido común puede ser transformado mediante intervenciones contrahegemónicas, y es aquí donde las prácticas culturales y artísticas pueden desempeñar un papel decisivo" (2014, p. 97). En palabras de Rancière, las prácticas artísticas "contribuyen a diseñar un paisaje nuevo de lo visible, lo decible y de lo factible. Ellas forjan contra el consenso otras formas de "sentido común", formas de un sentido común polémico" (2010, p.77). Sin embargo, al ser un sentido común polémico, el artista no tiene la intención de transmitir un mensaje en específico, pues si fuese así nos encontraríamos ante un modelo pedagógico. Actúa, más bien, con sus intervenciones sin querer trasmitir un mensaje tajante y sin saber lo que pasará o provocará su intervención, y solo alterando el orden, tanto físico como simbólico.

La articulación y el análisis de las estrategias que señalamos anteriormente: el relato etnográfico y el uso de la imagen, toma forma en un discurso analítico que intenta plasmar, en cada caso, el tipo de relaciones que se gestan entre la política y el arte. Es decir, que a partir de la experiencia narrada en el relato etnográfico y la descripción de la imagen de la obra artística a que dio lugar, se puede hacer una reflexión sobre las distintas concepciones del mundo y sobre una estructura social en las que estas intervenciones se inscriben. Así como la intervención per se y la manera en la que ésta altera y redistribuye la distribución de lo sensible. 
En las actuales formas de expresión artística encontramos múltiples voces que reconfiguran el espacio público y dan lugar a nuevas narrativas contrahegemónicas. La iniciativa por construir nuevas metodologías que nos acerquen a un análisis del campo del arte y la política, viene de un interés por indagar la relación que estas nuevas narrativas tienen con un modo de ser de lo social particular que responde al contexto actual.

A lo largo de este artículo desarrollamos una propuesta metodológica, basada en una comprensión de la estética como alteración de prácticas y modos habituales de concebir la vida social, a fin de analizar la relación arte-política que, por un lado, presenta una crítica al arte institucional que alberga objetos que se consumen desde un lugar de espectador pasivo y, por el otro, se centra en su capacidad de alterar el orden de lo sensible, estableciendo nuevos modos de ver, pensar y habitar el mundo. Para que una práctica u obra artística tenga un impacto social significativo, debe trabajar con los afectos y redireccionar el deseo hacia nuevos objetos. Esto, con el fin de que estos estén cada vez más cerca de la vida diaria y más lejos de una lógica de consumo capitalista. A su vez, esta "afectación" genera un proceso de des-identificación en los sujetos que permite que, aquello que parecía inamovible, se cuestione y dé lugar a nuevos mundos posibles.

Además, la intervención en el espacio público funge como un punto de encuentro que reconfigura las relaciones humanas y propone una redistribución de la esfera pública que le es arrebatada al Estado y a las empresas. Entonces, tanto la intervención en el espacio público como las relaciones que se gestan ahí, son dos ejes fundamentales de análisis a considerar para acercarse a estas prácticas estético-políticas.

Partiendo de estos dos ejes, desarrollamos tres estrategias metodológicas que, ante la multiplicidad de colectivos, movimientos y prácticas artísticas que existen, pensamos más como vías de exploración que como rígidos caminos que el investigador debe tomar. La primera es el relato etnográfico que se construye desde la experiencia del investigador en el espacio en donde se gestan estas prácticas artísticas, y que se apoya de entrevistas, relatos, imágenes, etc., $y$, por otro lado, del contexto en el que se desarrollan estas acciones, tomando en consideración el espacio y el tiempo al que están sujetas dichas prácticas artísticas. En ese sentido, estas prácticas tendrían una doble lectura: la primera tiene que ver con que son producidas por el mismo contexto histórico del que emergen y la segunda con que, al ser prácticas y discursos que están en constante tensión con un orden hegemónico del mundo, dan lugar a nuevos cuestionamientos, discursos y prácticas: a nuevas realidades.

La segunda estrategia metodológica es la descripción de las imágenes que, apoyada de la antropología visual, propone una relación profunda del investigador con las imágenes que las y los artistas producen en el campo mismo de la acción. Esta relación proviene de una observación minuciosa que se entrelaza con el relato etnográfico lo que, a su vez, da lugar a la tercera estrategia metodológica. Estas imágenes albergan un sinfín de significados que dan sentido a los discursos y a las prácticas de los artistas, o también pueden revelar otros. Es por ello que, acercarse al mundo de las prácticas estético-políticas, implica un arduo trabajo etnográfico que va de la mano del análisis de las imágenes. La tercera estrategia hace posible la utilización de la información obtenida con el relato etnográfico y con la descripción y análisis de las imágenes, como soporte para pensar los escenarios de confrontación estética y política, de disputa por las 
significaciones que están en juego y que, de algún modo, el arte callejero se encarga de develar.

Por último, nos interesa hacer énfasis en cómo pensamos la observación de las imágenes a lo largo del trabajo etnográfico. En el caso del investigador, la observación viene de una mirada activa que las decodifica y piensa a partir de sus propios símbolos. Esto también ocurre con los espectadores que transitan las calles, pues, aunque él o la artista busquen transmitir una idea concreta, las imágenes pasan por un proceso de resignificación cuando se depositan en el espacio público. Así, la producción estética en la calle adquiere una dimensión finita y entra en un contexto de transfiguración al abrirse a otras intervenciones. Desde el momento mismo de su puesta en escena, el o la artista se despoja de la obra que queda expuesta literalmente al otro. Hay pues un escenario de confrontación que la obra hace visible, pero su capacidad de convocatoria y la respuesta que produce le otorga al objeto estético nuevas significaciones.

\section{REFERENCIAS}

Allouch, J. (2015). Cuatro lecciones propuestas por Foucault al análisis, en Me cayó el veinte. Revista de psicoanálisis. No. 31 ¿Qué con la espiritualidad? México: Me cayó el veinte.

Arendt, H. (2005). La condición humana. Barcelona: Paidós.

Balbuena Mejía, Y. (2015). Fotografía para antropólogos. Ruta Antropológica. Revista electrónica, 3, 5-6. Disponible en: http:// www.posgrado.unam.mx/antropologia/revista/revista_03.pdf

Bishop, C. (2016). Infiernos artificiales Arte participativo y política de la espectaduría, Guadalajara:t-e-e oría.

Cabrera, R., Cano, M., Roa, K. y Vizcaíno, A. (2020). La ocupación de lo público. Una estética Transgresora. Documento dictaminado y aprobado para su publicación en la Revista Tramas. Subjetividad y procesos sociales, 52.

Capasso, V. y Bugnone, A. (2016). Arte y política: un estudio comparativo de Jacques Rancière y Nelly Richard para el arte latinoamericano. Bogotá: Hallazgos, 13 (26), 117-148. Recuperado de http://www.scielo.org.co/pdf/hall/v13n26/ v13n26a06.pdf

Collier, J., y Collier, M. (1986). Visual Anthropology: photography as a research method. The University of New Mexico press.

Deleuze, G. y Guattari, F. (1997). Mil Mesetas. Capitalismo y esquizofrenia. Valencia: Pre-Textos.

Foucault, M. (2003). Sobre la ilustración. Madrid. Tecnos. 
Freud, S. (1901). La interpretación de los sueños (segunda parte). Sobre el sueño (1900-1901). En Obras completas, vol. V. Buenos Aires, Argentina: Amorrortu editores.

García Beltran, S. (2019). La pátina de la memoria: Sobre las protestas feministas y el Ángel de la Independencia. Nexos. Recuperado de: https://labrujula.nexos.com.mx/?p=2463

García Canal, M. (Julio-diciembre de 2006). Multitudes. Revista CURARE espacio crítico para las artes, 27, 76-81.

García Collado, F. (2013). Análisis del concepto de deseo en Platón, Freud y Lacan frente a la crisis del sujeto contemporáneo (tesis doctoral). Universitat de Barcelona, Barcelona, España. Recuperado de: https://www.tdx.cat/bitstream/ handle/10803/130921/FJGC_TESIS.pdf?sequence=1

Jacknis, I. (1988). Margaret Mead and Gregory Bateson in Bali: Their Use of Photography and film. Cultural Anthropology, 3(2), 160-17. Recuperado de: http://www.jstor.org/stable/656349

Krotz, E. (1994). Alteridad y pregunta antropológica. Alteridades, 4(8), 5-11. Recuperado de https://www.redalyc.org/articulo. oa?id=747/74711353001

Lapoujade, M. (2001). Una mirada estética a lo invisible Revista de Filosofía de la Universidad de Costa Rica, 39(97), 11-20. Recuperado de http://www.inif.ucr.ac.cr/recursos/docs/ Revista\%20de\%20Filosof\%C3\%ADa\%20UCR/Vol.\%20XXXIX/ No.\%2097/Una\%20mirada\%20est\%C3\%A9tica\%20a\%20lo\%20 invisible.pdf

Mead, M. (1975). Visual Anthropology in a discipline of words. En P. Hockings (ed) Principles of visual anthropology. Mouton de Gruyter: Berlin.

Mouffe, Ch. (2014). Agonística: pensar el mundo políticamente. Ciudad Autónoma de Buenos Aires: Fondo de Cultura Económica.

Quintana, L. (2020). Política de los cuerpos. Barcelona, España: Herder.

Rabinow, P. (1992). Reflexiones sobre un trabajo de campo en Marruecos. Madrid: Ediciones Júcar.

Ranciére, J. (2005). Sobre políticas estéticas. Universidad Autónoma de Barcelona, Barcelona, España. 
Rancière, J. (2008). Estética y política: las paradojas del arte político. En Arte y política. Argentina, Brasil, Chile y España. Recuperado de https://webs.ucm.es/info/\%20artepltk/textos. html

Rancière, J. (2010). El espectador emancipado. Buenos Aires, Argentina: Ediciones Manantial SRL.

Restrepo, E. (2016). Etnografía: alcances, técnicas y éticas. Bogotá: Envión Editores. Disponible en: http://www.ram-wan. net/restrepo/documentos/libro-etnografia.pdf

Rodríguez, D. (2019, 27 de noviembre). Ellas son las chilenas que crearon 'Un violador en tu camino'. México: Verne en El País. Recuperado de https://verne.elpais.com/verne/2019/11/28/ mexico/1574902455_578060.html

Wodiczko, K. (s/f). The Tijuana Projection. Recuperado de https://www.krzysztofwodiczko.com/publicprojections?fbclid= IwAR251PaU_8aYzHZnyhtFwjpE1YIUg_DVeNbs5HUVkouS8RL_ gqLu3ODF6cl\#/new-gallery-79/

Troya, M.F. (2012). Un segundo encuentro: la fotografía etnográfica dentro y fuera del archivo, Íconos revista de ciencias sociales, 42. Antropología Visual en Latinoamérica. FLASCO, Ecuador. DOI: https://doi.org/10.17141/iconos.42.2012.458

Zirión Pérez, A. (2015). Miradas cómplices: cine etnográfico, estrategias colaborativas y antropología visual aplicada. Iztapalapa, Revista de Ciencias Sociales y Humanidades, 78, 45-70. Disponible en https://www.redalyc.org/articulo. oa?id=393/39348247003. 
1. https://verne.elpais.com/verne/2019/11/28/mexico/1574902455_578060.html

2. Con "pie de ladrón" nos referimos a la expresión coloquial que consiste en el acto de ayudar a alguien para alcanzar más alto, te ponen las manos entrelazadas debajo del pie y te apoyas en ellas.

3. @un_cursed. (7 de enero de 2019). 'No temas... ¿qué no estoy yo aquí que soy tu madre?’ Es un fragmento de lo que se adjudica a la virgen de Guadalupe cuando se le apareció a Juan Diego. Más del 83\% de la población mexicana es católica... ahí les habla su gfita... 'Ya no estoy yo aquí que soy tu madre... soy una de las 9 MUJERES QUE ASESINAN EN MEXICO TODOS LOS DÍAS'. [Fotografía]. Instagram. https://www.instagram.com/p/BsWyFZgFELK/

4. @brensue. (13 de abril de 2019). Lupita mostrándose como es en Regina Foto de @frantzishere thank you so much, it's the only photographic record of this drawing of Lupita. [Fotografía]. Instagram. https://www.instagram.com/p/BwOHuxI|4QX/ 